\title{
Iniciação científica em Letras com alunos da escola pública: letramento digital e produção de podcasts em língua inglesa no ensino fundamental *
}

\author{
Susana Cristina dos Reis (DLEM/UFSM, suzireis@cead.ufsm.br) \\ Luciane de Avila Botton (E.M.E.F. Júlio do Canto, lu51botton@gmail.com) \\ Rita Delourdes Brondani de Vargas (E.M.E.F. Júlio do Canto, ritadbv@gmail.com)
}

\begin{abstract}
Resumo
O ensino da habilidade oral ainda é uma competência linguística que precisa ser melhor trabalhada nas aulas de Língua Inglesa (LI) nas escolas públicas. Diante desse problema, este artigo apresenta um projeto de iniciação científica em Letras em desenvolvimento em uma escola da região central do Rio Grande do Sul, buscando investigar o uso de tecnologias digitais, tais como o podcast, em aulas de Inglês como língua estrangeira. Por meio de um estudo de caso, analisamos como o uso dessa ferramenta pode contribuir para promover a produção oral em LI. Iniciamos o projeto com o planejamento das atividades com vista a desenvolver fluência tecnológica dos alunos por meio da construção colaborativa de um blog. Após, aplicamos um questionário diagnóstico para identificarmos o perfil dos participantes. O projeto encontrase em fase inicial e os resultados obtidos apontam que embora haja efetiva propagação de tecnologias na sociedade, ainda há alunos que não têm acesso às mesmas em casa e, a maioria deles, não utiliza outros recursos tecnológicos além do computador. Nesse sentido, a escola tem papel fundamental em oportunizar a inserção de tecnologias nas atividades pedagógicas para garantir aos alunos o desenvolvimento de multiletramentos, inclusão social e tecnológica.
\end{abstract}

Palavras-chave: podcast. língua inglesa. escola pública.

\section{Language research assistants within the public schools: digital literacies and English podcast's production in the elementary classroom}

\begin{abstract}
The teaching of oral skills is still a linguistic competence that needs to be improved in English as a Foreign Language (EFL) classroom in public schools. Based on this, this paper presents a research project in Language studies under development at a school in the central region of Rio Grande do Sul, aiming to investigate the use of digital technologies such as podcasts in EFL classes. By a case study, we analyzed how the use of this tool can help to promote oral production in EFL. We began the project planning activities that could develop technological fluency and digital literacies of students by constructing a collaborative blog. Later, we applied a preliminary questionnaire to identify the participants' profile. The project is in its early stages and the initial results showed that although there is an effective spread of technologies into the society, most of students do not have access to those tools at home or do not use other technological device than their computers. In this sense, the school has a fundamental role in providing opportunities, inserting technology in pedagogical activities to ensure to students the development of multiliteracies, social and technological inclusion.
\end{abstract}

Keywords: podcast. english language. public school.

\section{Introdução}

Com a introdução de programas governamentais como o Ciências sem Fronteiras no Brasil (CSF), o qual visa "promover a consolidação, expansão e internacionalização da ciência e tecnologia, da inovação e da competitividade brasileira por meio do intercâmbio e da mobilidade internacional” (CSF, 2014), a necessidade de aprender Línguas Estrangeiras (LE) tem se tornado cada vez mais evidente tanto no contexto acadêmico quanto no escolar, já que exige dos alunos competências como falar e compreender línguas para competir e/ ingressar em instituições de ensino superior em países estrangeiros. 
apresentarem baixo nível de proficiência em Língua Inglesa (LI), não conseguem alcançar a pontuação mínima em testes de proficiência tais como no Test of English as a Foreign Language (TOEFL), fato este já evidenciando pela classificação que ocupa o Brasil no ranking mundial de proficiência em LI ( $38^{\circ}$ lugar), segundo mostram dados divulgados na mídia brasileira (Moreno, 2014). Com isso, percebemos que diante desses altos índices de reprovação em provas de proficiência, precisamos de iniciativas que busquem melhorar a qualidade de ensino de LE, bem como repensar a importância que damos ao ensino de línguas, inclusive, na escola básica.

A partir desses fatos, nos questionamos: Quem é (são) o(s) responsável(is) por esses índices de reprovação? Os alunos? Os professores? A escola? A testagem proposta? Afinal, como ensinamos LI aos nossos alunos no contexto escolar? Que habilidades linguísticas e/ou competências desenvolvemos nesse contexto? Que ações ou práticas pedagógicas podem ajudar (ou efetivamente melhorar) os atuais índices divulgados? Ao refletirmos sobre essas questões, percebemos que ainda não temos respostas a todos esses questionamentos, no entanto, ao trabalhar com professores da rede pública no Projeto Portal WebEnglish ${ }^{1}$, no ano de 2013, evidenciou-se que pouco a escola tem promovido atividades que preparem os alunos no que concerne à capacidade oral de comunicação em LE no contexto escolar e há diferentes fatores que contribuem para isso. Entre os fatores identificados, durante a aplicação do projeto, podemos citar: 1) a falta de qualificação dos professores para o desenvolvimento dessa competência linguística em sala de aula; 2) a falta de recursos no contexto escolar público para auxiliar na implementação mais efetiva da competência de oralidade em sala de aula.

De acordo com Miccoli (2006), são diversas as causas que levam a pouca prática da oralidade em sala de aula e, entre elas, a autora destaca:

\begin{abstract}
a dificuldade de se trabalhar com as quatro habilidades é uma experiência comum aos professores, que não conseguem principalmente implementar atividades para o desenvolvimento das habilidades de escuta e fala adequadas ao números de alunos em sala de aula. (MICCOLI, 2006, p.56).
\end{abstract}

Associado a esse problema, Silva (2011) acrescenta também três outros fatores que dificultam a inserção das práticas orais em sala de aula de escolas públicas, os quais são: o preconceito, o fator econômico e o social. O primeiro fator, o preconceito, o autor esclarece que é gerado pelos professores devido à falta de recursos didáticos para promover o desenvolvimento da habilidade oral em sala de aula. Já o segundo fator é o econômico e está relacionado às condições apresentadas pelos recursos tecnológicos disponíveis nas escolas públicas brasileiras. E, o último fator é o social, ou seja, a falta de um contexto social que efetivamente possibilite colocar em prática a oralidade. Isso deve-se principalmente porque nem o professor ou o aluno conseguem identificar um contexto prático de aplicação da aprendizagem da LI, já que não temos contato imediato com falantes de países estrangeiros que poderiam potencializar a prática efetiva da língua-alvo em estudo.

Entretanto, professores de LI precisam apostar em pesquisas que investiguem o uso de recursos que sejam favoráveis ao ensino e a aprendizagem da habilidade oral e, assim, valer-se deles (adaptando-os se for necessário) nas suas aulas de LE. Para isso, acreditamos que é papel da escola promover o uso de Tecnologias de Informação e Comunicação (TIC) no contexto escolar com vista a desenvolver competências que a sociedade cada vez mais cobra de nossos alunos. Na mesma direção, Belloni (2005) sugere que a escola deve ser um espaço integrador das TIC, pois estas já fazem parte das 
atividades diárias, cabendo à escola atuar no sentido de compensar as terríveis desigualdades sociais e regionais que são gerados pelo acesso desigual na sociedade.

Com base nessas discussões, este trabalho apresenta um projeto em desenvolvimento no contexto escolar público, da região central do Rio Grande do Sul, que introduz o uso de tecnologias no contexto escolar do ensino fundamental, buscando por meio de atividades de Iniciação Científica (IC) incentivar a prática da oralidade em LI por meio da ferramenta Podcast. Para isso, apresentamos dados iniciais que contextualizam a proposta do projeto, bem como o perfil dos participantes e as atividades iniciais realizadas para inserir os alunos na iniciação científica em sala de aula no contexto escolar público.

Pesquisas recentes têm apontado a ferramenta podcast como uma possível aliada ao desenvolvimento da oralidade, sem exigir alto nível de letramento digital por parte de seus usuários (Reis et al, 2012; Reis e Gomes, 2014; Tomé, 2012). Diante disso, é preciso investigar as potencialidades que ferramentas da Internet, tais como o podcast podem ofertar para promover a aprendizagem de LI, com o intuito de despertar nos alunos habilidades comunicativas, em situações de comunicação real na língua-alvo. Dessa forma, é importante buscar alternativas pedagógicas e recursos que favoreçam o desenvolvimento de atividades por meio dessa tecnologia.

Assim, neste artigo apresentamos discussões sobre o uso de podcast no ensino de línguas e o sugerimos como um rico recurso para a produção e prática da oralidade. Após, descrevemos os procedimentos metodológicos do projeto e as atividades realizadas até o presente momento. Por fim, propomos as considerações finais a partir dos dados obtidos por meio de um questionário diagnóstico que identifica o perfil dos participantes do projeto.

\section{$2 \mathrm{O}$ uso de podcast no ensino de línguas}

De acordo com estudos prévios, podcast é um recurso da Web 2.0 que permite o download de arquivos em áudio em diferentes formatos, na forma de episódios sonoros. Nesse recurso, a atualização instantânea dos arquivos é por meio do feed RSS (Real Simple Syndication), o qual proporciona ao usuário da Internet receber informações atualizadas sem a necessidade de visitar os sites de podcast um a um (Reis et al, 2012; RossellAguilar, 2009; Tomé, 2012). Portanto, é o uso do feed RSS que diferencia o podcast de um arquivo comum de áudio disponível na Web.

De acordo com Silva et al. (2012, p.11) "podcast é uma das mais modernas configurações entre os formatos sonoros disponíveis na Web”. O desenvolvimento dessa tecnologia iniciou-se em 2004, quando Adam Curry (DJ de MTV) e Dave Winer (criador de software) desenvolveram um programa que permitia descarregar automaticamente transmissões (broadcast) de rádio na Internet diretamente para os seus iPods. A partir disso, surgiu a combinação da palavra iPod e broadcast(ing), originando o termo Podcast(ing) (Reis et al., 2012; Carvalho e Moura, 2006).

De acordo com Bottentuit Junior e Coutinho (2007), entre as vantagens do uso dessas tecnologias no ensino estão: a) a compatibilidade a textos, imagens, vídeos, áudio e hipertextos; b) a não necessidade de amplos conhecimentos de informática para manusear tal recurso; c) a sua organização dos episódios por meio de posts, os quais podem ser produzidos de forma individual ou coletiva; d) o acesso de forma livre ou mediante registro ao conteúdo publicado. Além dessas vantagens, Barros e Menta (2007, p.75) acrescentam que podcasts "podem ser guardados no computador e/ou disponibilizados na Internet, podendo ainda ser vinculados a um arquivo de informação 
(ou feed) que permite que se assinem os programas, recebendo o utilizador as informações sem precisar de ir ao site do produtor."

No âmbito de sala de aula, o podcast é um recurso que já substitui o CD, na medida em que se verifica a existência de arquivos de áudios no formato mp3, tornando mais fácil a portabilidade (Gomes et al., 2011) desses arquivos, já que os alunos têm a sua disposição a possibilidade de gravar, avançar, retroceder e reproduzir esses arquivos de áudio quantas vezes forem necessárias para obterem melhores resultados de aprendizagem, seja acessando-os por meio de diferentes dispositivos móveis (inclusive, nos celulares), ou diretamente pela Internet.

Estudos que investigam o uso de podcast em sala de aula mostram que o processo de ensino pode ser beneficiado pelo uso desse recurso, pois ao entrar em contato com episódios de podcast os alunos podem adquirir novos vocabulários, realizar exercícios de compreensão oral, praticar oralidade ao produzir seu próprio podcast e ter acesso à uma grande fonte de materiais autênticos que são produzidos por falantes de línguas de diferentes locais do mundo (Furtoso e Gomes, 2011; Carvalho e Moura, 2006; Paiva e Bohn, 2008; Reis e Gomes, 2014).

No entanto, para que o uso desses recursos seja efetivo em sala de aula, Reis e Gomes (2014) sugerem que ao analisar podcasts é necessário considerar três critérios, ou seja, os aspectos pedagógicos, tecnológicos e linguísticos envolvidos neles. Com relação aos aspectos pedagógicos e linguísticos, a partir da investigação nos podcasts, os autores conceberam que é preciso:

1) analisar as concepções de linguagem dos autores produtores dos sites de podcast, bem como as abordagens que orientam os processos de ensino e de aprendizagem por meio das atividades disponíveis nos ambientes; 2) verificar os níveis de ensino a que tais materiais se destinam (básico, pré-intermediário, intermediário e avançado) e; 3) identificar as habilidades linguísticas que podem ser praticadas com o uso do recurso (Reis e Gomes, 2014, p.13).

Com relação aos aspectos tecnológicos, Reis e Gomes (2014) indicam que ao analisar e selecionar podcasts o professor deve avaliar o formato do recurso, a duração do episódio, a possibilidade de download, a transcrição dos áudios, a possibilidade de inserir comentários e como se dá a atualização dos episódios. Para os autores, ao observar esses aspectos tecnológicos pode-se garantir uma seleção mais apropriada de materiais para uso em sala de aula, especialmente, quando se tem como público-alvo alunos iniciantes em LI.

Tendo em vista essas discussões, na sequência apresentamos os procedimentos metodológicos adotados no desenvolvimento do projeto.

\section{Metodologia}

Esta pesquisa segue uma abordagem qualitativa, mais especificamente, trata-se de um estudo de caso, tendo como contexto de investigação a escola pública, com vista a verificar como o uso de podcast pode promover a produção oral e aprendizagem em LI. Esse projeto é uma das ações do GRPesq/CNPq - Núcleo de Pesquisa, Ensino e Aprendizagem de Línguas a Distância, da UFSM, em parceria com uma escola pública da rede municipal de Santa Maria, projeto financiado pela Fundação de Amparo à Pesquisa do Rio Grande do Sul, por meio do Edital PICMEL 3/2014. O projeto ainda é inicial e encontra-se em fase de desenvolvimento. Os dados apresentados contextualizam 
a proposta e apresentam dados sobre o perfil dos participantes, bem como algumas atividades de IC realizadas em sala de aula no contexto escolar público.

\subsection{Participantes do projeto}

Participam deste projeto duas professoras da escola e seis alunos do sexto e sétimo ano do Ensino Fundamental (EF). O projeto está sendo executado e supervisionado pelas professoras das áreas de Língua Inglesa e de Informática da escola parceira, sob a coordenação de uma professora do Departamento de Letras de uma Instituição de Ensino Superior (IES) de Santa Maria.

As professoras supervisoras do projeto possuem experiências com ensino há mais de dezessete anos em sala de aula. Quanto às experiências docentes e de formação, a professora de LI possui especialização, cursos de aperfeiçoamento de Informática e de metodologias aplicadas ao ensino de LI para professores estrangeiros, realizados em universidades japonesa e norte americana. A professora de Informática é licenciada em Matemática, com especialização em Informática Educacional e Tecnologias em Educação e utiliza efetivamente tecnologias em seu trabalho diário. Os alunos participantes realizam atividades de IC no projeto e estão na faixa etária entre doze e treze anos, sendo que destes quatro são meninos e duas meninas. Todos os meninos são de uma turma de sexto ano e as meninas do sétimo ano do EF.

\subsection{Contextos de desenvolvimento do projeto}

O projeto será realizado tanto na escola quanto na IES, sendo previsto diferentes encontros no turno inverso escolar dos alunos ao longo da execução do mesmo, o qual terá a duração de um ano letivo escolar, com previsão de término em setembro de 2015. Para realizar as atividades de IC, a escola conta com uma sala informatizada com 15 computadores e acesso à Internet. Na universidade, os alunos realizam suas atividades no Laboratório de Línguas, do Departamento de Letras Estrangeiras Modernas, cuja estrutura física conta com um laboratório com 24 computadores, acesso à Internet e demais recursos adquiridos para o projeto, os quais são notebooks, câmera digital e iPods para a execução das atividades de produção e de pesquisa.

\subsection{Instrumentos de coleta de dados na primeira fase do projeto}

Para este estudo serão utilizados como instrumentos de coleta de dados um questionário diagnóstico, elaborado com perguntas abertas e fechadas; os e-mails iniciais produzidos pelos alunos do projeto e o blog em que consta o registro das atividades do projeto. Para liberação das imagens das atividades produzidas durante o projeto, os pais responsáveis pelos alunos assinaram um termo de livre consentimento esclarecido para a divulgação dos dados e imagens referentes ao projeto em desenvolvimento.

É importante ressaltar também que, até o presente momento, os alunos tiveram apenas três encontros presenciais na escola, os quais são realizados quinzenalmente e, em cujos encontros ainda não produziram podcast em LI, pois encontram-se inicialmente familiarizando-se com as ferramentas tecnológicas para uso no projeto.

\section{Iniciação em Letras na escola pública: o que é e como fazer?}

Para incentivar a IC na escola pública, na área de Letras, buscamos desenvolver uma abordagem de ensino que pudesse envolver tanto os alunos quanto os professores nas atividades do Projeto Podc@st na Escol@. Para isso, delimitamos alguns papéis para 
cada participante do Projeto, entre eles estão os papéis desempenhados pela coordenação do projeto, bem como pelas professoras da escola e pelos alunos em IC.

A professora coordenadora da IES está responsável por: a) orientar as fases da presente pesquisa; b) orientar os professores supervisores no desenvolvimento das atividades do projeto; c) promover encontros na IES para qualificar tanto os professores supervisores quanto os alunos; d) incentivar a IC no contexto da escola pública, bem como estreitar relações entre a universidade e a escola pública por meio de ações de ensino, pesquisa e extensão intermediadas pelo projeto. As professoras pesquisadoras da escola pública são responsáveis por supervisionar as atividades de IC na escola pública, ao levar os alunos a desenvolverem pesquisa e a produzirem podcast para interagir em LI com outros falantes provenientes de outras escolas.

Para isso, partimos inicialmente de ações que tanto qualifiquem as professoras quanto os alunos do contexto escolar no desenvolvimento de competências para o uso de tecnologias, tornando-os capazes de agirem com mais autonomia nas atividades do Projeto. Por isso, a coordenação do projeto mantém encontros quinzenais com as professoras pesquisadoras, desafiando-as a buscar informações e dados para a partir deles preparar conteúdos/atividades de linguagem que podem auxiliar e agilizar a aprendizagem oral por meio de tecnologias digitais.

Para as professoras envolvidas no projeto, não foi necessário ofertar um módulo de letramento digital para qualificá-las quanto ao uso de tecnologias digitais em sala de aula, pois as mesmas são fluentes tecnologicamente, possuindo alto grau de familiaridade com tecnologias digitais, sendo habilitadas a pesquisar, selecionar e avaliar tecnologias para uso nas suas práticas diárias e, inclusive, em sala de aula.

Por outro lado, a partir da aplicação do questionário diagnóstico percebemos que os alunos deveriam primeiramente aprender sobre as ferramentas tecnológicas que serão utilizadas no projeto, para se tornarem fluentes e letrados digitalmente. A partir disso, elaboramos materiais didáticos digitais do projeto, especialmente as atividades que norteiam as atividades de pesquisa e ensino, tendo por referências as fases de produção de Material Didático Digital (MDD) propostas por Reis et al., (2012) e Reis e Gomes (2014).

\subsection{Planejando o desenvolvimento do Projeto de Podc@st na Escol@}

A partir do estudo das professoras pesquisadoras sobre o processo de elaboração de MDD, sob orientação da coordenação geral do projeto, iniciou-se o ciclo de produção dos MDD que seriam elaborados em reuniões realizadas sobre o projeto Podc@st na Escol@. Para isso, fez-se necessário conhecer o público-alvo e, posteriormente, planejaram-se as atividades de pesquisa e ensino. Os dados obtidos na fase de análise do ciclo de produção permitiram desenvolver o design dos materiais e das atividades de IC a serem construídos e disponibilizados no blog do projeto (Figura 1).

Nessa fase do projeto, a presente pesquisa foi realizada no laboratório de informática da escola. Para verificarmos o grau de letramento digital dos alunos com os podcasts e o seu desempenho quanto ao uso de ferramentas digitais durante as aulas, em prol de aprimorar a sua expressão oral, aplicamos um questionário diagnóstico. Os dados obtidos pelo questionário possibilitaram identificar o acesso dos alunos às tecnologias e seus graus de letramento digital com relação aos recursos em estudo. O questionário foi compartilhado via Google Drive e respondido nesse espaço virtual pelos alunos (Figura 1). Nesse momento, os alunos já possuíam cadastro de e-mail no servidor Gmail. 


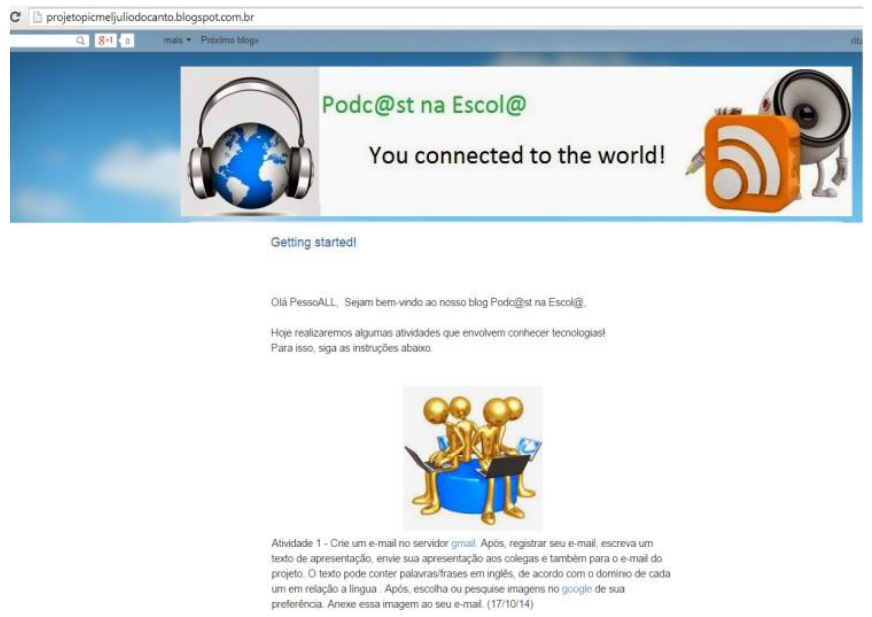

Figura 1 - Blog do Projeto Podc@st na Escol@

Fonte da imagem: https://projetopicmeljuliodocanto.blogspot.com.br/

O referido questionário foi respondido pelos seis alunos participantes do projeto. Nele buscamos evidenciar as tecnologias que os alunos possuíam acesso e em que locais as acessavam. Quanto ao quesito utilização de tecnologias (computador e Internet), todos os participantes afirmaram já fazer uso das mesmas. Em relação ao local de acesso às tecnologias, os resultados apontam que três alunos possuem acesso disponível em casa; um assinalou ainda as alternativas "na escola e na casa dos amigos"; somente um acessa “em lan houses” e apenas um possui acesso "na escola e na casa de amigos”. Quanto ao uso de outras tecnologias, tais como celulares, tablets e outras, dois alunos afirmaram utilizar celulares e quatro não utilizam nenhuma outra tecnologia.

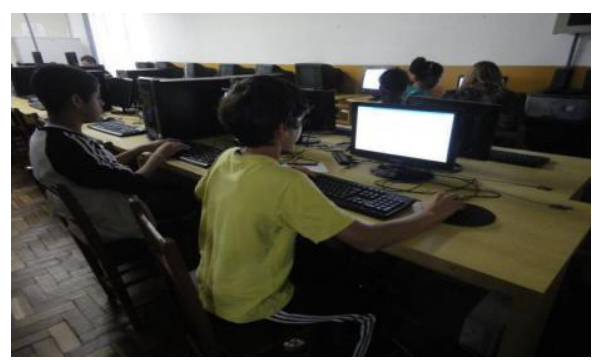

Figura 2 - Alunos trabalhando nas atividades do projeto Fonte da imagem: Arquivo da escola 2014

Ao investigarmos as TIC que os alunos mais utilizavam, no questionário foram citados o Facebook, Skype e E-mail. Entre os dados, um somente mencionou utilizar o Facebook; dois usam e-mail e um aluno respondeu que não utiliza nenhuma dessas tecnologias. Ao questionarmos sobre os recursos e sites que eles conheciam e sabiam utilizar, o YouTube e o Gmail são os mais conhecidos e usados pelos alunos, pois todos marcaram essas opções. O uso do Google e do Paint ficou em segundo lugar, já que cinco assinalaram essa opção.

Com relação à familiaridade dos alunos sobre a produção de vídeos com imagens e áudio, dois alunos afirmaram já terem produzidos vídeos e quatro não possuem experiência prévia. O mesmo aconteceu quando questionamos sobre a familiaridade deles com a postagem de vídeo na Internet. Por outro lado, ao sondarmos se os alunos assistiam a vídeos em Inglês na Internet, os resultados ficaram equilibrados, ou seja, três afirmaram assistir vídeos em inglês e outros três não assistem. 
Quando questionados sobre Podcasts, os alunos afirmaram que não conheciam ou utilizavam esse recurso, no entanto, quatro alunos afirmam que ouvem áudios em Inglês na Internet, evidenciando que embora não tenham acesso específico a sites de podcast sabem da existência de arquivos de áudios que são disseminados na Web, provavelmente, na forma de músicas, no formato mp3 ou mp4. A frequência dos alunos em assistir vídeos e ouvir músicas em Inglês na Internet demonstra que é por meio desse gênero que se efetiva o contato imediato dos alunos com a LI, pois nessa faixa etária os alunos já possuem preferências musicais e conhecem cantores e bandas estrangeiras, servindo de contexto imediato para a testagem de seus conhecimentos quanto à língua-alvo em estudo.

A pouca familiaridade dos alunos com o uso de podcast justifica e, também, motiva o desenvolvimento do projeto de IC na escola, pois sabemos que a partir da inserção do projeto nas atividades curriculares dos alunos, todos os participantes se beneficiarão do contato com essa tecnologia, bem como da possibilidade de produção oral em LI por meio desse recurso. Por outro lado, acreditamos ser necessário introduzir os alunos em contato com sites de podcast para que iniciem o seu uso a partir da seleção de alguns áudios dentro de certas temáticas para que, ao mesmo tempo, possam aprofundar conhecimentos linguísticos e tecnológicos.

Com base nesses resultados, observamos que, apesar do rápido avanço das TIC e da vasta abrangência que estas têm na sociedade atual, é surpreendente que ainda persistam alunos considerados nativos digitais com pouco acesso às tecnologias digitais em suas próprias casas. No entanto, isso deve-se ao fato de que a escola em estudo encontra-se em uma zona de periferia, na qual nem todos os alunos têm acesso à Internet em suas residências. Com isso, evidencia-se que cabe à escola oportunizar o acesso e garantir que esses alunos desenvolvam competências tão essenciais na contemporaneidade, de modo a garantir a inclusão social e tecnológica na sociedade atual, uma vez que esses alunos são nativos digitais e possuem facilidade para o uso de tecnologias digitais em suas atividades diárias.

Diante disso, atenta-se também para o fato de que não é suficiente as escolas serem beneficiadas com equipamentos de informática, por meio de programas governamentais, se a escola e os professores não buscarem aprimorar o uso destas tecnologias em suas práticas docentes, pois o simples acesso à tecnologia não é garantia de qualidade nos processos de ensino e de aprendizagem. Nesse sentido, concordamos com Cope e Kalantzis (2009, p. 168) que é apenas por meio de uma educação de qualidade, incluindo abordagens e tecnologias diversas, que podemos buscar diminuir as diferenças e desigualdades existentes na sociedade atual, pois, é por meio da educação que pode-se promover a inclusão social e tecnológica dos alunos e assim proporcionar a equidade social.

Portanto, é importante salientar que as mudanças proporcionadas pelo uso de tecnologias precisam ser "discutidas e absorvidas no contexto escolar com o objetivo de desenvolver multiletramentos nas práticas escolares para que alunos e professores sejam capazes de interagir dentro de uma multiplicidade de canais e mídias a sua disposição na sociedade” (Reis e Gomes, 2014, p.3). Para tanto, faz-se necessário inserir os alunos em práticas efetivas que os possibilitem interagir virtualmente, a fim de aprender a línguaalvo e aprimorar seus conhecimentos tecnológicos a favor da sua aprendizagem.

Com isso, entendemos que promover a fluência e o letramento digital dos alunos em sala de aula é apenas o primeiro passo para que possamos garantir o sucesso das atividades de IC, as quais serão realizadas pelos alunos no contexto escolar. Portanto, nessa fase da pesquisa, iniciamos as atividades envolvendo os alunos na construção colaborativa de um blog, bem como oportunizando a eles apreenderem as principais funcionalidades do e-mail do Gmail, além de alguns aplicativos do Google (drive, sharing 
form, agenda, entre outras.) para posteriormente realizarem as atividades de pesquisa na Internet que envolvem podcast.

\section{Considerações finais}

Os dados apresentados neste artigo são iniciais e demonstram as principais ideias do projeto aprovado pela FAPERGS, buscando promover a iniciação científica no contexto escolar. Pensamos que essa oportunidade única, ofertada por meio do edital PICMEL, reforça a postura de que precisamos promover no contexto escolar, a fim de tornar a escola um espaço de pesquisa, ensino, extensão e inovação científica, possibilitando aos alunos vivenciarem no contexto escolar competências tão essenciais no mundo contemporâneo, tais como o trabalho em equipe, a criatividade, a comunicação oral e escrita em LI, multiletramentos, fluência tecnológica e letramento digital. Dessa forma, oportunizamos a esses alunos tornarem-se cidadãos críticos, autônomos na seleção e produção de conhecimentos na Internet, por meio do desenvolvimento de pesquisa e avaliação criteriosa de conteúdos, bem como expondo suas opiniões e ideias, utilizando a linguagem e tecnologias variadas.

Como já salientamos, o projeto é inicial, por outro lado, esperamos que ao final da pesquisa os alunos possam dar sentido as suas aprendizagens e sintam-se motivados e habilitados a desenvolverem suas expressões orais com o auxílio das ferramentas tecnológicas, bem como, sejam cada vez mais, atuantes no mundo em que vivem e capacitados a interagir com outros por meio de diferentes formas de comunicação, não ficando limitados puramente às manifestações escritas da língua.

Diante do exposto, temos expectativas que o projeto irá promover e motivar os alunos na aprendizagem da língua adicional, já que na atual sociedade hipermidiática não é apenas essencial saber usar tecnologias a nosso favor, mas também é fundamental falar com proficiência uma língua estrangeira, para que possamos melhorar nossos índices de aprovação em provas de proficiência, como no TOEFL ou em outras estâncias de avaliação que abrem oportunidade de trabalho, de pesquisa e de estudos, tanto no Brasil quanto no exterior.

\footnotetext{
${ }^{1}$ Projeto Portal WebEnglish (http://www.ufsm.br/webenglish) configura-se em portal educacional online e, também, curso de formação continuada para professores de língua inglesa ofertado pela UFSM, em 2013, em parceria com o MEC, visando proporcionar aos professores de línguas formação continuada por meio de discussões que favorecem multiletramentos, a educação linguística e o letramento digital dos professores para atuação em sala de aula.
}

\section{Referências Bibliográficas}

BARROS, G. C., MENTA, E. Podcast: Produções de áudio para educação de forma crítica, criativa e cidadã. Revista de Economía Política de las Tecnologías de la Información y Comunicación, IX, n.1, 2007. p.74-89.

BELLONI, M. L. O que é mídia-educação. Coleção polêmicas do nosso tempo. São Paulo: Campinas. Autores Associados. 2.ed, 2005.

BOTTENTUIT JUNIOR, J. B.; COUTINHO, C. M. P. Blog e Wiki: os futuros professores e as ferramentas da Web 2.0. In: IX Simpósio Internacional de Informática Educativa. 2007. p.199-204. Disponível em: <http://siie2007.ese.ipp.pt/?id=pt>. Acesso em: 5 out. 2014.

CARVAlHO, A. A.; MOURA, A. Podcast: potencialidades na educação. Revista Prisma.com, n. 3, 2006. p. 88-110. Disponível em: <http://revistas.ua.pt/index.php/prismacom/article/view/623/pdf>. Acesso em: 20 jun. 2014. 
CIÊNCIA SEM FRONTEIRAS ONLINE (CSF). Site. 2014. Disponível em:< http://www.cienciasemfronteiras.gov.br/web/csf/o-programa>. Acesso em: 24 Nov. 2014.

COPE, B.; KALANTZIS, M. Multiliteracies: new literacies, new learning. Pedagogies: an Internacional Journal, v.4, n.3, 2009. p. 164-185. Disponível em: <http://dx.doi.org/10.1080/15544800903076044> Acesso em: 20 jun. de 2014.

\begin{abstract}
FURTOSO, V.; GOMES, M. J. Aprendizagem e avaliação da oralidade em contextos online - o potencial dos serviços de podcasting. Disponível em: <http://repositorium.sdum.uminho.pt/bitstream/1822/12854/3/gomes-viviane.pdf>. Acesso em: 17 jun. 2014.
\end{abstract}

GOMES, A.F; SÁ, C.G; FIALHO, V. R. Podcast: uma opção didática para o ensino de E/LE. $5^{\circ}$ Congresso Nacional de Ambientes Hipermídia Para Aprendizagem (CONAHPA). Anais. Pelotas. set de 2011. Disponível em:<http://wright.ava.ufsc.br/ alice/conahpa/anais/2011/papers/20.pdf>. Acesso em: 5 out. 2014.

MICCOLI, L. Experiências de professores no ensino de língua inglesa: uma categorização com implicações para o ensino e a pesquisa. UFMG. Linguagem e Ensino. v.10, n.1, p.47-86, jan./jul. 2006. Disponível em: <http://www.rle.ucpel.tche.br/index.php/rle/article/view/155/122>. Acesso em: 02 nov. 2014.

MORENO, A. Com proficiência baixa em inglês, Brasil fica estagnado em ranking. In: GLOBO.G1 Site. Seção Educação. Disponível em:<http:/g1.globo.com/educacao/noticia/2014/11/com-proficiencia-baixaem-ingles-brasil-fica-estagnado-em-ranking.html>. Acesso em: 14 Nov. 2014.

PAIVA, V. L. M. O.; BOHN, V. C. R. O uso de tecnologias em aulas de LE. 2008. Disponível em: <http://www.veramenezes.com/paivabohn.pdf>. Acesso em: 20 jun. 2014.

REIS, S. C., GOMES, A. Podcasts para o ensino de Língua Inglesa: análise e prática de Letramento Digital. $\begin{array}{lllllll}\text { Caleidoscópio. } & \text { v. } & 12, & \text { n. } & 3, & 2014 . & \text { Disponível em: }\end{array}$ <http://revistas.unisinos.br/index.php/calidoscopio/article/view/cld.2014.123.11>. Acesso em: $30 \mathrm{dez}$. 2014.

REIS, S. C.; GOMES, A. F.; LINCK, A. J. M. 2012. Uso de Podcast no Ensino de Língua Inglesa: Um estudo de caso. Revista Escrita, v. 15, 2012. p.1-18

ROSELL-AGUILAR, F. 2009. Podcasting for language learning: re-examining the potential. In: L. LOMICKA; G. LORD (eds.) The next generation: social networking and online collaboration in foreign language learning. $8^{\mathrm{a}}$ ed., Texas, USA, Editora CALICO, p. 13-34.

SILVA. A.; DUQUE. L. V.; SILVA. P. S. O uso de podcasts no desenvolvimento da oralidade em língua inglesa. Revista Pesquisas em Discurso Pedagógico, n. 2, 2012. Disponível em: $<$ http://www.maxwell.vrac.puc-rio.br/rev_discurso.php?strSecao=input0>. Acesso em: 14. Jun. 2014.

SILVA, M. S. Dificuldades do ensino na oralidade em aulas de língua inglesa. Revista Fronteira Digital, n. 4. Ano II. Ago/Dez, 2011, p. 92-99. Disponível em: <http://www.unemat.br/revistas/fronteiradigital/docs/artigos/n4_2011/fronteira_digital_n4_2011_art_7.pd f> Acesso em: 5 de out. 2014.

TOMÉ, I. Uso do podcast no ensino-aprendizagem: estudo de caso. In: BOTTENTUIT JUNIOR, J.B.; COUTINHO, C.P. (org.), Educação On-line: conceitos, metodologias, ferramentas e aplicações, $1^{\text {a }}$ ed., Curitiba, Editora CRV, 2012. p. 147-164. 